\title{
Roles of vascular and metabolic components in cognitive dysfunction of Alzheimer disease: short- and long-term modification by non-genetic risk factors
}

\author{
Naoyuki Sato ${ }^{1,2}$ * and Ryuichi Morishita ${ }^{1}$ * \\ 1 Department of Clinical Gene Therapy, Graduate School of Medicine, Osaka University, Osaka, Japan \\ ${ }^{2}$ Department of Geriatric Medicine, Graduate School of Medicine, Osaka University, Osaka, Japan
}

\author{
Edited by: \\ Jan Klohs, Eidgenössische Technische \\ Hochschule Zurich, Switzerland \\ Reviewed by: \\ Thomas Mueggler, University and \\ Eidgenössische Technische \\ Hochschule Zurich, Switzerland \\ David Alexander Drachman, \\ University of Massachusetts Medical \\ School, USA

\section{${ }^{*}$ Correspondence:} \\ Naoyuki Sato, Department of Clinical \\ Gene Therapy, Graduate School of \\ Medicine, Osaka University, 2-2 \\ Yamada-oka, Suita, Osaka 565-0871, \\ Japan; Department of Geriatric \\ Medicine, Graduate School of \\ Medicine, Osaka University, 2-2 \\ Yamada-oka, Suita, Osaka 565-0871, \\ Japan \\ e-mail:nsato@cgt.med.osaka-u.ac.jp; \\ Ryuichi Morishita, Department of \\ Clinical Gene Therapy, Osaka \\ University, Graduate School of \\ Medicine, 2-2 Yamada-oka, Suita, \\ Osaka 565-0871, Japan \\ e-mail:morishit@ \\ cgt.med.osaka-u.ac.jp
}

It is well known that a specific set of genetic and non-genetic risk factors contributes to the onset of Alzheimer disease (AD). Non-genetic risk factors include diabetes, hypertension in mid-life, and probably dyslipidemia in mid-life. This review focuses on the vascular and metabolic components of non-genetic risk factors. The mechanisms whereby non-genetic risk factors modify cognitive dysfunction are divided into four components, short- and long-term effects of vascular and metabolic factors. These consist of (1) compromised vascular reactivity, (2) vascular lesions, (3) hypo/hyperglycemia, and (4) exacerbated AD histopathological features, respectively. Vascular factors compromise cerebrovascular reactivity in response to neuronal activity and also cause irreversible vascular lesions. On the other hand, representative short-term effects of metabolic factors on cognitive dysfunction occur due to hypoglycemia or hyperglycemia. Non-genetic risk factors also modify the pathological manifestations of AD in the long-term. Therefore, vascular and metabolic factors contribute to aggravation of cognitive dysfunction in AD through shortterm and long-term effects. $\beta$-amyloid could be involved in both vascular and metabolic components. It might be beneficial to support treatment in $A D$ patients by appropriate therapeutic management of non-genetic risk factors, considering the contributions of these four elements to the manifestation of cognitive dysfunction in individual patients, though all components are not always present. It should be clarified how these four components interact with each other. To answer this question, a clinical prospective study that follows up clinical features with respect to these four components: (1) functional MRI or SPECT for cerebrovascular reactivity, (2) MRI for ischemic lesions and atrophy, (3) clinical episodes of hypoglycemia and hyperglycemia, (4) amyloid-PET and tau-PET for pathological features of $A D$, would be required.

Keywords: diabetes mellitus, hypertension, dyslipidemia, Alzhimer's disease, abeta, tauopathies

\section{INTRODUCTION}

The number of dementia patients is over 30 million worldwide (Dartigues, 2009). Alzheimer disease (AD) accounts for about $50 \%$ of cases. Though AD is a progressive neurodegenerative disorder, clinical therapy for this devastating disease is still limited to choline esterase inhibitors and $N$-methyl-D-aspartate activated receptor antagonists. $\mathrm{AD}$ is pathologically characterized by cerebral atrophy, particularly of the hippocampus as well as temporal and parietal lobes, and microscopically by senile plaques, neurofibrillary tangles (NFT), and neuronal cell death. $\beta$-amyloid (A $\beta$ ), a peptide consisting of 38-43 amino acids, was discovered in cerebral amyloid angiopathy (CAA; Glenner and Wong, 1984) and senile plaques. Subsequently, amyloid precursor protein (APP) was cloned based on the A $\beta$ sequence. Familial AD has

Abbreviations: APP, amyloid precursor protein; CAA, cerebral amyloid angiopathy; IGF-1, insulin-like growth factor-1; IRS-2, insulin receptor substrate-2; LRP-1, LDL receptor related protein-1; NSY, Nagoya-Shibata-Yasuda mouse; RAGE, receptor for advanced glycation end products. been found to be caused by mutations in APP and presenilin (Levy-Lahad et al., 1995; Rogaev etal., 1995; Sherrington etal., 1995). Both mutations cause overproduction of $A \beta$, particularly its longer form, $A \beta 42$, which is more prone to aggregate, although the mechanism whereby presenilin mutations increase $A \beta 42 / A \beta 40$ ratio is still under investigation (De Strooper et al., 2012; Haass et al., 2012; Sato et al., 2012a). On the other hand, sporadic cases comprise more than $95 \%$ of $\mathrm{AD}$. Although some drugs based on the $A \beta$ hypothesis are in clinical trials, the search for alternative therapeutic targets against AD should be encouraged. Such targets could emerge from an understanding of the mechanisms whereby risk factors increase the incidence of sporadic AD. Genetic and non-genetic risk factors contribute to sporadic AD (Fotuhi et al., 2009). APOE\&4 is the strongest genetic risk factor for sporadic $\mathrm{AD}$. APOE\&4 promotes the development of senile plaques, although its mechanism is yet to be determined. On the other hand, non-genetic risk factors include diabetes (Ott et al., 1999), hypertension (Takeda et al., 2008) and dyslipidemia in mid-life (Shepardson et al., 2011a). However, the mechanisms by which 
these non-genetic risk factors may modify cognitive function have not been coordinately understood. Here, we summarize these mechanisms by dividing them into four components (Figure 1), and propose clinical application of this concept in order to understand the pathogenesis of cognitive dysfunction in individual patients. These are short- and long-term effects of vascular and metabolic factors: (1) compromised vascular reactivity, (2) vascular lesions, (3) hypo/hyperglycemia, and (4) exacerbated AD histopathological features, respectively. Vascular factors compromise cerebrovascular reactivity in response to neuronal activity and also cause irreversible vascular lesions. On the other hand, representative short-term effects of metabolic factors on cognitive function occur due to hypoglycemia and hyperglycemia. Nongenetic risk factors also modify the pathological manifestations of $\mathrm{AD}$ in the long-term. Therefore, vascular and metabolic components contribute to aggravation of cognitive dysfunction in $\mathrm{AD}$ through short-term and long-term effects.

\section{HYPERTENSION AND AD}

The number of patients with hypertension is now estimated to be approximately 40 million. One half of these patients are untreated, and half of those receiving treatment are poorly controlled (Prince, 1997). Epidemiological studies showed that patients who developed dementia showed an increase in blood pressure from mid-life through to late-life, compared to those who did not develop dementia (Stewart et al., 2009). Pathological investigations also indicate that hypertension causes an increase

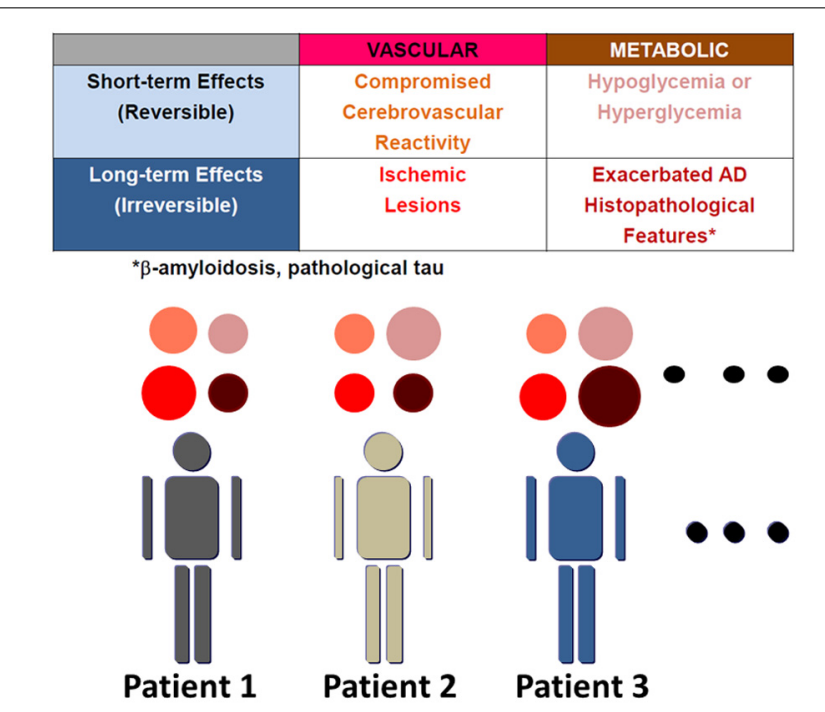

FIGURE 1 | Variable mechanisms by which AD patients with nongenetic risk factors manifest cognitive dysfunction. The mechanisms whereby non-genetic risk factors modify cognitive dysfunction are divided into four elements: short- and long-term effects of vascular and metabolic factors. These are (1) compromised vascular reactivity, (2) vascular lesions, (3) hypo/hyperglycemia, and (4) exacerbated AD histopathological features, respectively. AD histopathological features include $\beta$-amyloidosis and pathological tau. $\beta$-amyloid also compromises vascular reactivity and causes microhemorrhages due to cerebral amyloid angiopathy. The contribution of these four elements to manifestation of cognitive dysfunction varies among patients, though all components must not always be present. in white matter lesions (Firbank et al., 2007). Therefore, hypertension causes vascular lesions such as stroke, white matter lesions, and microhemorhages, which might cause cognitive dysfunction. In addition, hypertension might cause functional cerebrovascular abnormalities. Therefore, hypertension mainly modifies $\mathrm{AD}$ through vascular factors, though it might have an influence on pathological processes in $\mathrm{AD}$ as discussed later.

\section{DIABETES AND AD}

Numerous epidemiological studies have also demonstrated that patients with diabetes have a significantly higher risk of developing AD (Kopf and Frolich, 2009; Maher and Schubert, 2009). However, the mechanism whereby diabetes increases the risk of $\mathrm{AD}$ is not fully understood. In the Rotterdam study, diabetes almost doubled the risk of dementia and AD (Ott et al., 1999). In a Japanese cohort, the Hisayama study also indicated that glucose intolerance increased the incidence of AD two to fourfold. Moreover, a metaanalysis of 14 studies also confirmed that diabetes increases the risk of AD (Kopf and Frolich, 2009).

\section{DYSLIPIDEMIA AND AD}

Midlife dyslipidemia could also be a risk factor for AD (Shepardson et al., 2011a), although it is reported that late-life dyslipidemia might be protective against AD (Mielke et al., 2005). Though whether dyslipidemia is a risk for $\mathrm{AD}$ is still controversial, it is noteworthy that statins might have preventive effects against AD (Shepardson et al., 2011b). Retrospective cohort studies by Wolozin etal. (2000) and Jick etal. (2000) independently suggested that statin users had a lower prevalence of dementia. However, a randomized controlled study failed to show beneficial effects on the cognitive decline in $\mathrm{AD}$ (Feldman et al., 2010). On the other hand, the Rotterdam study, a prospective cohort study, demonstrated that compared to non-statin users and non-statin lipid-lowing drug users, users of both lipophilic and hydrophilic statins had a lower incidence of AD by nearly a half (Haag etal., 2009). Therefore, statins could prevent or delay the onset of $\mathrm{AD}$, but not slow cognitive decline once the disease has set in (Sato et al., 2012b). Several studies have already shown that statins might reduce the $A \beta$ level in the brain (Fassbender et al., 2001; Burns et al., 2006; Ostrowski et al., 2007; Kurinami et al., 2008). Thus, dyslipidemia and use of statins could have opposite influences on cognitive function through different mechanisms.

\section{SHORT-TERM MODIFICATION BY VASCULAR FACTORS}

Cognition is closely related to cerebrovascular function (Iadecola et al., 2009; Dickstein et al., 2010). Short-term modification by vascular factors is mediated through reversible dysfunction of vascular reactivity to neuronal stimulation. Non-genetic risk factors such as hypertension and diabetes compromise vascular reactivity. Hypertension reduces cerebrovascular reactivity in humans (Griffith et al., 1978; Maeda et al., 1994). Hypertension causes deterioration of cerebrovascular function through physical pressure load and angiotensin-mediated signal transduction. On the other hand, it is also well known that diabetic complications involve microangiopathy (Muris et al., 2012). Indeed, diabetes affects vascular reactivity (Caballero et al., 1999; Pasquier 
et al., 2006). Moreover, our study using animals suggested that diabetes increases $A \beta$ accumulation in the cerebral vasculature (Takeda et al., 2010b). Therefore, diabetes could aggravate vascular reactivity through multiple pathways including hyperglycemia, hyperinsulinemia, and increased $A \beta$ accumulation. In fact, $A \beta$ itself reduces endothelial function in vitro (Hayashi et al., 2009) and vascular reactivity in mice (Niwa et al., 2000) and humans (Dumas et al., 2012). Moreover, we confirmed that an angiotensin receptor blocker improved cognitive function and restored cerebrovascular function in an $\mathrm{AD}$ mouse model through reduction of $\mathrm{A} \beta$-induced cellular stress (Takeda et al., 2009a). Therefore, vascular factors compromise cerebrovascular function through physical pressure load, osmotic load, angiotensin or insulin signal, and $\mathrm{A} \beta$ load.

\section{LONG-TERM MODIFICATION BY VASCULAR FACTORS}

Alzheimer disease with cerebrovascular disease is more common than previously recognized. It is understandable that cerebrovascular lesions aggravate cognitive function in $\mathrm{AD}$ patients (Richard and Pasquier, 2012). As hypertension and diabetes increase cerebrovascular lesions, these non-genetic risk factors for $\mathrm{AD}$ increase the risk of $\mathrm{AD}$ by increasing cerebrovascular lesions as well.

\section{HYPERTENSION AND VASCULAR LESIONS}

It has been indicated that mid-life hypertension is a risk factor for the development of AD (Skoog et al., 1996; Launer et al., 2000; Kivipelto et al., 2001; Takeda et al., 2008). As hypertension increases cerebrovascular necrosis and arteriosclerosis, antihypertensive therapies could suppress cognitive function decline (Peters et al., 2008; Takeda etal., 2008). In the Syst-Eur study, a randomized controlled study, antihypertensive medication, which included nitrendipine, enalapril and hydrochlorothiazide, in elderly hypertensive patients decreased the onset risk not only for vascular dementia, but also for AD (Forette etal., 2002). In addition, SCOPE, Study on Cognition and Prognosis in the Elderly, found that candesartan, an angiotensin receptor blocker, inhibited cognitive deterioration in patients with mild cognitive impairment (Skoog et al., 2005). A recent meta-analysis of studies including HYVET-cog (Hypertension in the Very Elderly Trial cognitive function assessment) indicated that the occurrence of dementia is significantly reduced by antihypertensive treatment (Peters et al., 2008). To determine whether antihypertensive therapy can prevent dementia requires a study setting dementia prevention as a primary endpoint. The OSCAR study (Observational Study on Cognitive function And systolic blood pressure Reduction) was conducted to confirm whether hypertensive patients treated with eprosartan show improvement in MMSE score (Shlyakhto, 2007). Results from a subgroup of OSCAR are supportive of the hypothesis that this treatment may be associated with preservation of cognitive function (Radaideh et al., 2011). Another report from OSCAR of a retrospective investigation suggested that blood pressure responses after treatment coincided with stabilization of MMSE in difficult-to-treat hypertensive patients (Petrella et al., 2012). Therefore, further clinical studies are warranted to clarify whether antihypertensive drugs could prevent dementia and inhibit progression of the disease.

\section{DIABETES AND VASCULAR LESIONS}

Diabetes also increases cerebrovascular lesions (van Elderen et al., 2010), which aggravates cognitive dysfunction in AD. To understand the mechanism whereby diabetes increases the risk of $\mathrm{AD}$, we generated $\mathrm{AD}$ model mice with a diabetic phenotype by crossbreeding APP Tg mice and leptin-deficient $o b / o b$ mice. We examined $\mathrm{A} \beta$ burden in the cerebral vessels in $\mathrm{APP}^{+}{ }_{-} o b / o b$ and found that these mice had more severe CAA than did single APP Tg mice (Takeda et al., 2010b). CAA is one of the major characteristics observed in $\mathrm{AD}$ and vascular aging. CAA triggers hemorrhagic (Greenberg and Vonsattel, 1997) and contributes to the clinical presentation of dementia (Pfeifer et al., 2002). We also found that $\mathrm{APP}^{+}-\mathrm{ob} / \mathrm{ob}$ mice showed up-regulation of RAGE, the receptor for AGE (Brownlee et al., 1988), in the vasculature. It is reported that RAGE mediates amplification of inflammatory responses (Basta et al., 2002). Indeed, inflammatory cytokines such as IL-6 and $\mathrm{TNF} \alpha$ were upregulated around the cerebrovasculature in $\mathrm{APP}^{+}$ob/ob (Takeda et al., 2010b). Therefore, diabetes also could affect cerebrovascular vascular lesions through increased expression of RAGE and subsequent chronic inflammation.

\section{STATINS AND VASCULAR LESIONS}

Dyslipidemia is also a risk factor for vascular disease, especially cardiovascular disease. Whether dyslipidemia is a risk for cerebrovascular disease is relatively unclear, probably because the power of dyslipidemia to promote cardiovascular disease is too strong. Anti-dyslipidemia statins are protective against vascular change. In clinical studies, statins have been shown to prevent secondary stroke (Ni Chroinin et al., 2013). Several published studies, including ours, demonstrated that statins restored cognitive function after experimental stroke through their pleiotropic effects (Shimamura et al., 2007; Mayanagi et al., 2008). Because hypertension and diabetes, in addition to dyslipidemia, increase the risk of stroke, statins could prevent worsening of cognitive dysfunction in $\mathrm{AD}$ patients with these common diseases.

\section{SHORT-TERM MODIFICATION BY METABOLIC FACTORS}

Diabetic patients experience hyperglycemia or hypoglycemia during dietary and drug control of plasma glucose levels. Both these conditions have an influence on patients' cognitive dysfunction. Because the brain uses mainly glucose as an energy source, hypoglycaemia causes defects of neuronal function, though lactate can also be used in this situation (Rasmussen et al., 2011; Wyss et al., 2011). Failure of neuronal networking including cholinergic and GABAergic pathways also might contribute to cognitive impairment in a hypoglycemic state (Sherin et al., 2012). On the other hand, hyperglycemia also compromises cognitive dysfunction, due to ketoacidosis and a hyperglycemic hyperosmotic state. Cognitive dysfunction due to hyperglycemia or hypoglycemia is reversible. However, repeated episodes of severe hypoglycemia are reported to also be a risk for the development of dementia (Whitmer et al., 2009).

\section{LONG-TERM MODIFICATION BY METABOLIC FACTORS HYPERTENSION AND AD PATHOLOGY}

Hypertension could possibly modify $\mathrm{AD}$ risk by increasing the pathological progression of $\mathrm{AD}$ in addition to ischemic lesions. 
In a study of autopsied brain, the incidence of senile plaques and NFT in hypertensive patients was approximately 2 and 4 times higher than control, respectively (Sparks et al., 1995). Interestingly, it is reported that valsartan, an angiotension receptor blocker, improved cognitive deterioration in $\mathrm{AD}$ model mice through anti-A $\beta$ effects; that is, inhibition of $A \beta$ oligomerization and promotion of $A \beta$ degradation by an insulin-degrading enzyme (Wang et al., 2007). However, the mechanism by which hypertension increases $\mathrm{AD}$ risk needs further investigation because the underlying mechanisms are not so straightforward.

\section{DIABETES AND A $\beta$}

Epidemiological and neuropathological studies have provided many important insights into the mechanism whereby diabetes increases the risk of AD. A cohort study indicated that insulin resistance in mid-life is associated with the development of senile plaques in later life (Matsuzaki et al., 2010). In contrast, retrospective studies suggested that the magnitude of senile plaques and NFT was comparable between AD patients with and without diabetes (Kalaria, 2009). These results seem to contradict each other. Several groups reported that a high-fat diet caused $\mathrm{A} \beta$ accumulation in the brain of wild type rabbits (Sparks et al., 1994) and APP Tg mice. There are several proposed mechanisms for this phenomenon, such as compromised autophagy in an insulinresistant condition (Son et al., 2012) and upregulation of BACE1, which cleaves APP, in a diabetic condition (Guglielmotto et al., 2012). Although feeding a high-fat diet caused severe memory deficit in APP Tg with NSY background (Nagoya-Shibata-Yasuda) mice, which are established as an inbred animal model with spontaneous development of diabetes (Shibata and Yasuda, 1980; Ueda et al., 2000), we observed no increase in brain A $\beta$ load by a highfat diet (Takeda et al., 2010b). Similarly, we found no difference in brain $\mathrm{A} \beta$ accumulation between $\mathrm{APP}^{+}{ }_{-}-o b / o b$ and APP mice without diabetes (Takeda et al., 2010b). These findings as to whether diabetes increases $\mathrm{A} \beta$ accumulation in the $\mathrm{AD}$ mouse brain seem to be inconsistent. The magnitude of inflammation evoked by diabetes, which activates microglia to clear $A \beta$, might be involved in this inconsistency.

\section{DIABETES AND BRAIN INSULIN SIGNALING}

Insulin signaling might be impaired in the $\mathrm{AD}$ and diabetic brain. Insulin receptors are ubiquitous in the cortex and hippocampus (Havrankova et al., 1978; Hill et al., 1986; Wickelgren, 1998), and circulating insulin accesses the brain by crossing the blood-brain barrier (Banks, 2004). In the advanced AD brain, the levels of insulin and IGF (insulin-like growth factor)-1 were significantly reduced relative to controls (Rivera et al., 2005). After insulin binds to the insulin receptor, which activates its tyrosine kinase, IRS-1 protein undergoes tyrosine phosphorylation and binds phosphatidylinositol 3-kinase (PI3K; Sun et al., 1991), which activates AKT and glycogen-synthase kinase-3 $\beta$ (GSK3 $\beta$; Sutherland et al., 1993; Cross et al., 1995; Neumann et al., 2008). In vitro, $\mathrm{A} \beta$ increases tau phosphorylation through AKT-GSK3 $\beta$ (Tokutake et al., 2012). Consistent with this result, the AD brain manifested reduced responses to insulin and IGF-1 signaling (Talbot etal., 2012). The levels and activities of the insulin$\mathrm{PI} 3 \mathrm{~K}-\mathrm{AKT}$ pathway were also reported to be decreased in $\mathrm{AD}$ and diabetic brains (Liu etal., 2011). Consistent with these human studies, our $\mathrm{APP}^{+}-\mathrm{ob} / \mathrm{ob}$ mice also manifested impaired insulin signaling in the brain (Takeda et al., 2010b). These results raise the possibility that impaired insulin signaling might be involved in the pathogenesis of $\mathrm{AD}$ with or without diabetes (Sato et al., 2011; Takeda et al., 2011). Similarly, IGF-1, IGF-2 and their receptors also exist in the CNS (Shemer et al., 1987; Rotwein et al., 1988; Araujo et al., 1989; Chen et al., 2011). Importantly, brain-specific insulin receptor knockout mice showed no alteration in the brain (Schubert et al., 2004), suggesting compensation of IGF receptor signaling for insulin signaling. Taken together, these findings indicate that insulin/IGF signaling might be impaired in the $\mathrm{AD}$ with diabetes brain, and this signaling might have an impact on aging and disease-related brain dysfunction.

\section{INSULIN SIGNALING AND A $\beta$}

The next question is whether impaired insulin signaling has any influence on $A \beta$ metabolism. In vitro studies suggested that insulin/IGF signaling is involved in $\mathrm{A} \beta$ generation, clearance, and trafficking (Gasparini et al., 2001; Carro et al., 2006; Freude et al., $2009 b$ ). While soluble $A \beta$ oligomers and $A \beta$ aggregates are in equilibrium (Sato et al., 2006), reduced IGF signaling is reported to decrease soluble $A \beta$ oligomers, increasing $A \beta$ aggregates (Cohen et al., 2009). In contrast, another group reported that a reduction of IGF signaling decreased $\mathrm{A} \beta$ deposition, suggesting an opposite shift (Freude et al., 2009a). Similarly, loss of a downstream mediator of insulin/IGF signaling, IRS (insulin receptor substrate)-2, is reported to reduce $A \beta$ deposition (Freude et al., 2009a; Killick et al., 2009). Moreover, it is also reported that suppression of the insulin receptor also decreased $\mathrm{A} \beta$ deposition (Murakami et al., 2011). Our $\mathrm{APP}^{+}{ }_{-} o b / o b$ mice manifested a reduction in insulin signaling with no change in brain $A \beta$ level, but increased $A \beta$ deposition in the cerebral vasculature (Takeda et al., 2010b). Therefore, although the effects of insulin signaling on $\mathrm{A} \beta$ metabolism are not so simple, we speculate that reduced insulin signaling might affect control of protein quality and quantity in diabetic $\mathrm{AD}$ mice.

\section{DIABETES AND TAU}

Diabetes could also exacerbate tau phosphorylation and formation of NFT. Although tau physiologically promotes the assembly and stabilization of microtubules, hyperphosphorylated tau sequesters normal tau, and disrupts microtubules (Iqbal et al., 1994, 2009). Retrospective clinicopathological studies suggested that the magnitude of NFT is comparable in AD with and without diabetes (Kalaria, 2009), though a retrospective study might reflect the features at the end stage of the disease. On the other hand, many groups reported that diabetes increased tau phosphorylation in mouse models. Importantly, in the human diabetic brain, tau phosphorylation is increased at the same sites as hyperphosphorylated in AD (Liu et al., 2009). These studies indicate that diabetes could increase tau phosphorylation, leading to the development of NFT.

\section{INSULIN SIGNALING AND TAU PHOSPHORYLATION}

Indeed, impaired insulin signaling could cause tau phosphorylation. As mentioned above, insulin signaling is well known to be 
mediated through the PI3K-AKT pathway, with downstream involvement of GSK3 $\beta$ (Sutherland etal., 1993; Cross et al., 1995; Neumann etal., 2008). Because GSK3 $\beta$ phosphorylates tau, insulin inhibits tau phosphorylation in neurons through the inhibition of GSK3 $\beta$ via AKT (Hong and Lee, 1997). In contrast, loss of insulin (Schechter etal., 2005), insulin receptor (Schubert et al., 2004), or IRS-2 (Schubert et al., 2003; Freude etal., 2009a; Killick et al., 2009) results in an increase of tau phosphorylation. These findings indicate that impaired insulin signaling might increase tau phosphorylation. In general, protein phosphorylation is also regulated by phosphatases. Tau is reported to be dephosphorylated by protein phosphatase $2 \mathrm{~A}$ (Sontag et al., 1996). Moreover, disruption of IRS-2 also downregulates protein phosphatase 2A (Sontag et al., 1996). Therefore, impaired insulin signaling might cause tau phosphorylation by influencing both kinases and phosphatases. Taken together, these findings indicate it is possible that diabetes could promote tau phosphorylation via impaired insulin signaling in the brain.

\section{MODIFICATION OF DIABETIC PHENOTYPE BY AD}

It is also noteworthy that $\mathrm{AD}$ could affect diabetic phenotype. Several clinical reports have suggested that $\mathrm{AD}$ patients manifest glucose intolerance (Bucht et al., 1983; Meneilly and Hill, 1993; Janson et al., 2004). Consistent with these clinical observations, we found that $\mathrm{AD}$ aggravated the diabetic phenotype in two different lines of APP Tg mice with diabetes (Takeda et al., 2010b; Sato etal., 2011). We can speculate on the mechanisms whereby $\mathrm{AD}$ affects the diabetic phenotype. First, $\mathrm{AD}$ could compromise central control of peripheral glucose metabolism (van de Nes et al., 1998), as recent evidence suggests an important role of the central nervous system in control of glucose homeostasis (Demuro and Obici, 2006; Prodi and Obici, 2006). Second, plasma $A \beta$ could mediate peripheral insulin resistance. We previously reported that plasma $A \beta$ level increases after glucose loading in AD transgenic mice (Takeda et al., 2009b, 2010a), and could change after oral glucose loading in AD patients (Takeda et al., 2012). Therefore, increased plasma A $\beta$ might affect insulin signaling directly in peripheral tissues (Sato and Morishita, 2013; Zhang et al., 2013). Third, $A \beta$ accumulation could occur in the pancreas (Miklossy et al., 2008) and skeletal muscle (Roher et al., 2009), thereby impairing insulin secretion and insulin resistance, respectively. In clinical settings, AD patients might have worse glucose control because they cannot take medication and eat properly. Indeed, poor cognitive function also increases the risk of severe hypoglycemia in patients with type 2 diabetes (Punthakee et al., 2012).

\section{EFFECT OF STATINS ON A $\beta$ PRODUCTION}

As mentioned above, anti-dyslipidemia drugs, statins, might have a preventive effect against $\mathrm{AD}$. We investigated the mechanisms responsible for the reduction of $A \beta$ in the brain by statins. First, $\mathrm{A} \beta$ reduction is associated with a reduction in the carboxyl terminal fragment of APP (APP-CTF; Shinohara et al., 2010). Statins reduce the brain $A \beta$ level through increasing APP-CTF trafficking by inhibition of protein isoprenylation. In general, $A \beta$ level is balanced between its production and clearance. We also found that statins reduce brain $A \beta$ level through enhanced $A \beta$ clearance mediated by up-regulation of LRP-1 (LDL receptor related protein-1) expression. Therefore, we can expect an additional effect of brain $A \beta$ reduction by statins to decrease vascular events. There are reports suggesting that statins might transiently and reversibly impair cognitive function (Orsi et al., 2001; King et al., 2003; Wagstaff et al., 2003), especially if the drug is firstly administered to treat patients aged over 75 years. Despite these several reports of statin-associated cognitive impairment, this adverse effect remains a rare occurrence (Rojas-Fernandez and Cameron, 2012). Considering the beneficial effects, statins should be used with close attention to the emergence of adverse effects in elderly patients. Recent PET studies of amyloid confirmed that $A \beta$ begins to accumulate in the brain one or two decades before the manifestation of memory impairment in AD. Statins in mid-life might prevent the onset of $\mathrm{AD}$ by reducing $\mathrm{A} \beta$ production by enhancing APP-CTF degradation and up-regulating $\mathrm{A} \beta$ clearance in the brain. There are over 30,000,000 patients taking statins, and they might benefit from $A \beta$ reduction in the brain in addition to the cholesterol-lowering effect (Sato et al., 2012b).

\section{CONCLUSION AND PERSPECTIVE}

Non-genetic risk factors, such as diabetes, hypertension, and dyslipidemia, modify cognitive dysfunction in AD. The mechanisms of these consequences are divided into four components. These are short- and long-term effects of vascular and metabolic factors: (1) compromised vascular reactivity, (2) vascular lesions, (3) hypo/hyperglycemia, and (4) exacerbated AD histopathological features, respectively. $\beta$-amyloid could be involved in both vascular and metabolic components. It might be beneficial to support treatment in $\mathrm{AD}$ patients by appropriate therapeutic management of non-genetic risk factors, considering the contributions of these four elements to the manifestation of cognitive dysfunction in individual patients, though all components may not always be present. It should be clarified how these four components interact with each other. To answer this question, a clinical prospective study that follows up clinical features with respect to these four components: (1) functional MRI or SPECT for cerebrovascular reactivity, (2) MRI for ischemic lesions and atrophy, (3) clinical episodes of hypoglycemia and hyperglycemia, and (4) amyloid-PET and tau-PET for pathological features of $\mathrm{AD}$, would be required. Understanding the interaction of the four components will help to elucidate the role of vascular and metabolic factors in cognitive dysfunction of $\mathrm{AD}$ and provide beneficial knowledge for the treatment of $\mathrm{AD}$ patients with or even without non-genetic risk factors.

\section{ACKNOWLEDGMENTS}

This work was supported in part by grants-in-aid from Japan Promotion of Science, the Japanese Ministry of Education, Culture, Sports, Science, and Technology (to Naoyuki Sato and Ryuichi Morishita), the Japan Science and Technology Agency (to Naoyuki Sato), Novartis Gerontological Research Grants, Chiyoda, Kanae Foundation, and the Takeda Science Foundation (to Naoyuki Sato). 


\section{REFERENCES}

Araujo, D. M., Lapchak, P. A., Collier, B., Chabot, J. G., and Quirion, R. (1989). Insulin-like growth factor1 (somatomedin-C) receptors in the rat brain: distribution and interaction with the hippocampal cholinergic system. Brain Res. 484, 130-138. doi: 10.1016/0006-8993(89)90355-7

Banks, W. A. (2004). The source of cerebral insulin. Eur. J. Pharmacol. 490, 5-12. doi: 10.1016/j.ejphar. 2004.02.040

Basta, G., Lazzerini, G., Massaro, M., Simoncini, T., Tanganelli, P., Fu, C., et al. (2002). Advanced glycation end products activate endothelium through signal-transduction receptor RAGE: a mechanism for amplification of inflammatory responses. Circulation 105, 816-822. doi: 10.1161/hc0702.104183

Brownlee, M., Cerami, A., and Vlassara, H. (1988). Advanced glycosylation end products in tissue and the biochemical basis of diabetic complications. N. Engl. J. Med. 318, 1315-1321. doi: 10.1056/ NEJM198805193182007

Bucht, G., Adolfsson, R., Lithner, F., and Winblad, B. (1983). Changes in blood glucose and insulin secretion in patients with senile dementia of Alzheimer type. Acta Med. Scand. 213, 387-392. doi: 10.1111/j.09546820.1983.tb03756.x

Burns, M. P., Igbavboa, U., Wang, L., Wood, W. G., and Duff, K (2006). Cholesterol distribution, not total levels, correlate with altered amyloid precursor protein processing in statin-treated mice. Neuromol. Med. 8, 319-328. doi: 10.1385/ NMM:8:3:319

Caballero, A. E., Arora, S., Saouaf, R., Lim, S. C., Smakowski, P., Park, J. Y., et al. (1999). Microvascular and macrovascular reactivity is reduced in subjects at risk for type 2 diabetes. Diabetes 48, 1856-1862. doi: 10.2337/diabetes.48.9.1856

Carro, E., Trejo, J. L., Spuch, C., Bohl, D., Heard, J. M., and TorresAleman, I. (2006). Blockade of the insulin-like growth factor I receptor in the choroid plexus originates Alzheimer's-like neuropathology in rodents: new cues into the human disease? Neurobiol. Aging 27, 1618-1631. doi: 10.1016/j.neurobiolaging.2005.09.039

Chen, D. Y., Stern, S. A., GarciaOsta, A., Saunier-Rebori, B., Pollonini, G., Bambah-Mukku, D., et al. (2011). A critical role for IGF-II in memory consolidation and enhancement. Nature 469, 491-497. doi: 10.1038 /nature09667
Cohen, E., Paulsson, J. F., Blinder, P., Burstyn-Cohen, T., Du, D., Estepa, G., et al. (2009). Reduced IGF-1 signaling delays age-associated proteotoxicity in mice. Cell 139, 11571169. doi: 10.1016/j.cell.2009.11.014

Cross, D. A., Alessi, D. R., Cohen, P., Andjelkovich, M., and Hemmings, B. A. (1995). Inhibition of glycogen synthase kinase- 3 by insulin mediated by protein kinase B. Nature 378, 785-789. doi: 10.1038/378785a0

Dartigues, J. F. (2009). Alzheimer's disease: a global challenge for the 21st century. Lancet Neurol. 8, 1082 1083. doi: 10.1016/S1474-4422(09) 70298-4

Demuro, G., and Obici, S. (2006). Central nervous system and control of endogenous glucose production. Curr. Diab. Rep. 6, 188-193. doi: 10.1007/s11892-006-0033-8

De Strooper, B., Iwatsubo, T., and Wolfe, M. S. (2012). Presenilins and gamma-secretase: structure, function, and role in Alzheimer Disease. Cold Spring Harb. Perspect. Med. 2, a006304. doi: 10.1101/cshperspect.a006304

Dickstein, D. L., Walsh, J., Brautigam, H., Stockton, S. D. Jr., Gandy, S., and Hof, P. R. (2010). Role of vascular risk factors and vascular dysfunction in Alzheimer's disease. Mt. Sinai J. Med. 77, 82-102. doi: 10.1002/msj.20155

Dumas, A., Dierksen, G. A., Gurol, M. E., Halpin, A., Martinez-Ramirez, S. Schwab, K., et al. (2012). Functional magnetic resonance imaging detection of vascular reactivity in cerebral amyloid angiopathy. Ann. Neurol. 72 , 76-81. doi: 10.1002/ana.23566

Fassbender, K., Simons, M., Bergmann, C., Stroick M., Lutjohann, D., Keller, P., et al. (2001). Simvastatin strongly reduces levels of Alzheimer's disease beta-amyloid peptides Abeta 42 and Abeta 40 in vitro and in vivo. Proc. Natl. Acad. Sci. U.S.A. 98, 5856-5861. doi: 10.1073/pnas.081620098

Feldman, H. H., Doody, R. S., Kivipelto, M., Sparks, D. L., Waters, D. D. Jones, R. W., et al. (2010). Randomized controlled trial of atorvastatin in mild to moderate Alzheimer disease: LEADe. Neurology 74, 956-964. doi: 10.1212/WNL.0b013e3181d6476a

Firbank, M. J., Wiseman, R. M., Burton, E. J., Saxby, B. K., O’Brien, J. T., and Ford, G. A. (2007). Brain atrophy and white matter hyperintensity change in older adults and relationship to blood pressure. Brain atrophy, WMH change and blood pressure. J. Neurol. 254, 713-721. doi: 10.1007/s00415-006-0238-4

Forette, F., Seux, M. L., Staessen, J. A., Thijs, L., Babarskiene, M. R.,
Babeanu, S., et al. (2002). The prevention of dementia with antihypertensive treatment: new evidence from the Systolic Hypertension in Europe (Syst-Eur) study. Arch. Intern. Med. 162, 2046-2052. doi: 10.1001/archinte.162.18.2046

Fotuhi, M., Hachinski, V., and Whitehouse, P. J. (2009). Changing perspectives regarding late-life dementia. Nat. Rev. Neurol. 5, 649 658. doi: 10.1038/nrneurol.2009.175

Freude, S., Hettich, M. M., Schumann, C., Stohr, O., Koch, L., Kohler, C., et al. (2009a). Neuronal IGF-1 resistance reduces Abeta accumulation and protects against premature death in a model of Alzheimer's disease. FASEB J. 23, 3315-3324. doi: 10.1096/fj.09-132043

Freude, S., Schilbach, K., and Schubert, M. (2009b). The role of IGF-1 receptor and insulin receptor signaling for the pathogenesis of Alzheimer's disease: from model organisms to human disease. Curr. Alzheimer Res. 6, 213-223. doi: 10.2174/156720509788486527

Gasparini, L., Gouras, G. K., Wang, R., Gross, R. S., Beal, M. F., Greengard, P., et al. (2001). Stimulation of betaamyloid precursor protein trafficking by insulin reduces intraneuronal beta-amyloid and requires mitogenactivated protein kinase signaling. $J$. Neurosci. 21, 2561-2570.

Glenner, G. G., and Wong, C. W. (1984). Alzheimer's disease: initia report of the purification and characterization of a novel cerebrovascular amyloid protein. Biochem. Biophys. Res. Commun. 120, 885-890. doi 10.1016/S0006-291X(84)80190-4

Greenberg, S. M., and Vonsattel, J. P. (1997). Diagnosis of cerebral amyloid angiopathy. Sensitivity and specificity of cortical biopsy. Stroke 28, 1418-1422. doi: 10.1161/01.STR.28. 7.1418

Griffith, D. N., James, I. M., Newbury, P. A., and Woollard, M. L. (1978). Abnormal cerebrovascular regulation in hypertensive patients. Br. Med. J. 2, 740. doi: 10.1136/bmj.2.6139.740

Guglielmotto, M., Aragno, M., Tamagno, E., Vercellinatto, I., Visentin, S., Medana, C., etal. (2012). AGEs/RAGE complex upregulates BACE1 via NF-kappaB pathway activation. Neurobiol. Aging 33, 196e13-196e27. doi: 10.1016/j. neurobiolaging.2010.05.026

Haag, M. D., Hofman, A., Koudstaal, P. J., Stricker, B. H., and Breteler, M. M. (2009). Statins are associated with a reduced risk of Alzheimer disease regardless of lipophilicity. The Rotterdam Study. J. Neurol.
Neurosurg. Psychiatry 80, 13-17. doi: 10.1136/jnnp.2008.150433

Haass, C., Kaether, C., Thinakaran, G., and Sisodia, S. (2012). Trafficking and proteolytic processing of APP. Cold Spring Harb. Perspect. Med. 2, a006270. doi: 10.1101/cshperspect.a006270

Havrankova, J., Roth, J., and Brownstein, M. (1978). Insulin receptors are widely distributed in the central nervous system of the rat. Nature 272, 827-829. doi: 10.1038/272827a0

Hayashi, S., Sato, N., Yamamoto, A., Ikegame, Y., Nakashima, S., Ogihara, T., etal. (2009). Alzheimer disease-associated peptide, amyloid beta40, inhibits vascular regeneration with induction of endothelial autophagy. Arterioscler. Thromb. Vasc. Biol. 29, 1909-1915. doi: 10.1161/ATVBAHA.109.188516

Hill, J. M., Lesniak, M. A., Pert, C. B., and Roth, J. (1986). Autoradiographic localization of insulin receptors in rat brain: prominence in olfactory and limbic areas. Neuroscience 17, 1127-1138. doi: 10.1016/0306-4522(86)90082-5

Hong, M., and Lee, V. M. (1997). Insulin and insulin-like growth factor-1 regulate tau phosphorylation in cultured human neurons. J. Biol. Chem. 272, 19547-19553. doi: 10.1074/jbc.272.31.19547

Iadecola, C., Park, L., and Capone, C. (2009). Threats to the mind: aging, amyloid, and hypertension. Stroke 40, S40-S44. doi: 10.1161/STROKEAHA.108.533638

Iqbal, K., Alonso, A. C., Gong, C. X., Khatoon, S., Singh, T. J., and Grundke-Iqbal, I. (1994). Mechanism of neurofibrillary degeneration in Alzheimer's disease. Mol. Neurobiol. 9, 119-123. doi: 10.1007/BF02816111

Iqbal, K., Liu, F., Gong, C. X., Alonso Adel, C., and GrundkeIqbal, I. (2009). Mechanisms of tauinduced neurodegeneration. Acta Neuropathol. 118, 53-69. doi: 10.1007/s00401-009-0486-3

Janson, J., Laedtke, T., Parisi, J. E., O’Brien, P., Petersen, R. C., and Butler, P. C. (2004). Increased risk of type 2 diabetes in Alzheimer disease. Diabetes 53, 474-481. doi: 10.2337/diabetes.53.2.474

Jick, H., Zornberg, G. L., Jick, S. S., Seshadri, S., and Drachman, D. A. (2000). Statins and the risk of dementia. Lancet 356, 16271631. doi: 10.1016/S0140-6736(00) 03155-X

Kalaria, R. N. (2009). Neurodegenerative disease: diabetes, microvascular pathology and Alzheimer disease. 
Nat. Rev. Neurol. 5, 305-306. doi: 10.1038/nrneurol.2009.72

Killick, R., Scales, G., Leroy, K., Causevic, M., Hooper, C., Irvine, E. E., et al. (2009). Deletion of Irs2 reduces amyloid deposition and rescues behavioural deficits in APP transgenic mice. Biochem. Biophys. Res. Commun. 386, 257-262. doi: 10.1016/j.bbrc.2009.06.032

King, D. S., Wilburn, A. J., Wofford, M. R., Harrell, T. K., Lindley, B. J., and Jones, D. W. (2003). Cognitive impairment associated with atorvastatin and simvastatin. Pharmacotherapy 23, 1663-1667. doi: 10.1592/phco.23.15.1663.31953

Kivipelto, M., Helkala, E. L., Hanninen, T., Laakso, M. P., Hallikainen, M., Alhainen, K., et al. (2001). Midlife vascular risk factors and late-life mild cognitive impairment: a populationbased study. Neurology 56, 1683 1689. doi: 10.1212/WNL.56.12.1683

Kopf, D., and Frolich, L. (2009). Risk of incident Alzheimer's disease in diabetic patients: a systematic review of prospective trials. J. Alzheimers Dis. 16, 677-685. doi: 10.3233/JAD-20091011

Kurinami, H., Sato, N., Shinohara, M., Takeuchi, D., Takeda, S., Shimamura, M., et al. (2008). Prevention of amyloid beta-induced memory impairment by fluvastatin, associated with the decrease in amyloid beta accumulation and oxidative stress in amyloid beta injection mouse model. Int. J. Mol. Med. 21, 531-537.

Launer, L. J., Ross, G. W., Petrovitch, H., Masaki, K., Foley, D., White, L. R., et al. (2000). Midlife blood pressure and dementia: the HonoluluAsia aging study. Neurobiol. Aging 21, 49-55. doi: 10.1016/S01974580(00)00096-8

Levy-Lahad, E., Wasco, W., Poorkaj, P., Romano, D. M., Oshima, J., Pettingell, W. H., et al. (1995). Candidate gene for the chromosome 1 familial Alzheimer's disease locus. Science 269, 973-977. doi: 10.1126/science.7638622

Liu, Y., Liu, F., Grundke-Iqbal, I., Iqbal, K., and Gong, C. X. (2011). Deficient brain insulin signalling pathway in Alzheimer's disease and diabetes. J. Pathol. 225, 54-62. doi: 10.1002/path.2912

Liu, Y., Liu, F., Grundke-Iqbal, I., Iqbal, K., and Gong, C. X. (2009). Brain glucose transporters, O-GlcNAcylation and phosphorylation of tau in diabetes and Alzheimer's disease. J. Neurochem. 111, 242-249. doi: 10.1111/j.1471-4159.2009.06320.x

Maeda, H., Matsumoto, M., Handa, N., Hougaku, H., Ogawa, S., Itoh,
T., et al. (1994). Reactivity of cerebral blood flow to carbon dioxide in hypertensive patients: evaluation by the transcranial Doppler method. J. Hypertens. 12, 191-197. doi: 10.1097/00004872-199402000-00012

Maher, P. A., and Schubert, D. R. (2009). Metabolic links between diabetes and Alzheimer's disease. Expert Rev. Neurother. 9, 617-630. doi: 10.1586/ern.09.18

Matsuzaki, T., Sasaki, K., Tanizaki, Y., Hata, J., Fujimi, K., Matsui, Y., et al. (2010). Insulin resistance is associated with the pathology of Alzheimer disease: the Hisayama study. Neurology 75, 764-770. doi: 10.1212/WNL.0b013e3181eee25f

Mayanagi, K., Katakam, P. V., Gaspar, T., Domoki, F., and Busija, D. W. (2008). Acute treatment with rosuvastatin protects insulin resistant $(\mathrm{C} 57 \mathrm{BL} / 6 \mathrm{~J} \mathrm{ob} / \mathrm{ob})$ mice against transient cerebral ischemia. J. Cereb. Blood Flow Metab. 28, 1927-1935. doi: $10.1038 / j \mathrm{cbfm} .2008 .81$

Meneilly, G. S., and Hill, A. (1993). Alterations in glucose metabolism in patients with Alzheimer's disease. J. Am. Geriatr. Soc. 41, 710-714. doi: 10.1056/NEJM198509053131013

Mielke, M. M., Zandi, P. P., Sjogren, M., Gustafson, D., Ostling, S., Steen, B., et al. (2005). High total cholesterol levels in late life associated with a reduced risk of dementia. Neurology 64, 1689-1695. doi: 10.1212/01. WNL.0000161870.78572.A5

Miklossy, J., Qing, H., Radenovic, A., Kis, A., Vileno, B., Laszlo, F., et al. (2008). Beta amyloid and hyperphosphorylated tau deposits in the pancreas in type 2 diabetes. Neurobiol. Aging 31, 1503-1515. doi: 10.1016/j.neurobiolaging.2008.08.019 Murakami, K., Yokoyama, S., Murata, N., Ozawa, Y., Irie, K., Shirasawa, T., et al. (2011). Insulin receptor mutation results in insulin resistance and hyperinsulinemia but does not exacerbate Alzheimer's-like phenotypes in mice. Biochem. Biophys. Res. Commun. 409, 34-39. doi: 10.1016/j.bbrc.2011.04.101

Muris, D. M., Houben, A. J., Schram, M. T., and Stehouwer, C. D. (2012). Microvascular dysfunction is associated with a higher incidence of type 2 diabetes mellitus: a systematic review and meta-analysis. Arterioscler. Thromb. Vasc. Biol. 32, 3082-3094. doi: 10.1161/ATVBAHA.112.300291

Neumann, K. F., Rojo, L., Navarrete, L. P., Farias, G., Reyes, P., and Maccioni, R. B. (2008). Insulin resistance and Alzheimer's disease: molecular links \& clinical implications.
Curr. Alzheimer Res. 5, 438-447. doi: 10.2174/156720508785908919

Ni Chroinin, D., Asplund, K. Asberg, S., Callaly, E., CuadradoGodia, E., Diez-Tejedor, E., et al. (2013). Statin therapy and outcome after ischemic stroke: systematic review and meta-analysis of observational studies and randomized trials. Stroke 44, 448-456. doi: 10.1161/STROKEAHA.112.668277

Niwa, K., Younkin, L., Ebeling, C. Turner, S. K., Westaway, D., Younkin, S., et al. (2000). Abeta 1-40-related reduction in functional hyperemia in mouse neocortex during somatosensory activation. Proc. Natl. Acad. Sci. U.S.A. 97, 9735-9740. doi: 10.1073/pnas.97.17.9735

Orsi, A., Sherman, O., and Woldeselassie, Z. (2001). Simvastatin-associated memory loss. Pharmacotherapy 21, 767-769. doi: 10.1592/phco.21.7.767.34577

Ostrowski, S. M., Wilkinson, B. L., Golde, T. E., and Landreth, G. (2007). Statins reduce amyloidbeta production through inhibition of protein isoprenylation. J. Biol. Chem. 282, 26832-26844. doi: 10.1074/jbc.M702640200

Ott, A., Stolk, R. P., van Harskamp, F., Pols, H. A., Hofman, A., and Breteler, M. M. (1999). Diabetes mellitus and the risk of dementia: the Rotterdam Study. Neurology 53, 1937-1942. doi: 10.1212/WNL.53.9.1937

Pasquier, F., Boulogne, A., Leys, D., and Fontaine, P. (2006). Diabetes mellitus and dementia. Diabetes Metab. 32(Pt 1), 403-414. doi: 10.1016/S1262 3636(07)70298-7

Peters, R., Beckett, N., Forette, F., Tuomilehto, J., Clarke, R., Ritchie, C., etal. (2008). Incident dementia and blood pressure lowering in the hypertension in the very elderly trial cognitive function assessment (HYVET-COG): a double-blind, placebo controlled trial. Lancet Neurol. 7, 683-689. doi: 10.1016/S1474-4422(08)70143-1

Petrella, R. J., Shlyakhto, E., Konradi, A. O., Berrou, J. P., Sedefdjian, A., and Pathak, A. (2012). Blood pressure responses to hypertension treatment and trends in cognitive function in patients with initially difficult-to-treat hypertension: a retrospective subgroup analysis of the Observational Study on Cognitive Function and SBP Reduction (OSCAR) study. J. Clin. Hypertens. (Greenwich) 14, 7884. doi: $10.1111 / \mathrm{j} .1751-7176.2011$. 00577.x

Pfeifer, L. A., White, L. R., Ross, G. W., Petrovitch, H., and Launer, L.
J. (2002). Cerebral amyloid angiopathy and cognitive function: the HAAS autopsy study. Neurology 58, 1629 1634. doi: 10.1212/WNL.58.11.1629

Prince, M. J. (1997). The treatment of hypertension in older people and its effect on cognitive function. Biomed. Pharmacother. 51, 208-212. doi: 10.1016/S0753-3322(97)81597-1

Prodi, E., and Obici, S. (2006). Minireview: the brain as a molecular target for diabetic therapy. Endocrinology 147, 2664-2669. doi: 10.1210/en.2006-0143

Punthakee, Z., Miller, M. E., Launer, L. J., Williamson, J. D., Lazar, R. M., Cukierman-Yaffee, T., et al. (2012). Poor cognitive function and risk of severe hypoglycemia in type 2 diabetes: post hoc epidemiologic analysis of the ACCORD trial. Diabetes Care 35, 787-793. doi: 10.2337/dc111855

Radaideh, G. A., Choueiry, P., Ismail, A., Eid, E., Berrou, J. P., Sedefdjian, A., et al. (2011). Eprosartanbased hypertension therapy, systolic arterial blood pressure and cognitive function: analysis of middle east data from the OSCAR study. Vasc. Health Risk Manag. 7, 491-495. doi: 10.2147/VHRM.S19699

Rasmussen, P., Wyss, M. T., and Lundby, C. (2011). Cerebral glucose and lactate consumption during cerebral activation by physical activity in humans. FASEB J. 25, 2865-2873. doi: 10.1096/fj.11-183822

Richard, F., and Pasquier, F. (2012). Can the treatment of vascular risk factors slow cognitive decline in Alzheimer's disease patients? J. Alzheimers Dis. 32, 765-772. doi: 10.3233/JAD-2012121012 .

Rivera, E. J., Goldin, A., Fulmer, N., Tavares, R., Wands, J. R., and de la Monte, S. M. (2005). Insulin and insulin-like growth factor expression and function deteriorate with progression of Alzheimer's disease: link to brain reductions in acetylcholine. J. Alzheimers Dis. 8, 247-268.

Rogaev, E. I., Sherrington, R., Rogaeva, E. A., Levesque, G., Ikeda, M., Liang, Y., et al. (1995). Familial Alzheimer's disease in kindreds with missense mutations in a gene on chromosome 1 related to the Alzheimer's disease type 3 gene. Nature 376, 775-778. doi: $10.1038 / 376775 \mathrm{a} 0$

Roher, A. E., Esh, C. L., Kokjohn, T. A., Castano, E. M., Van Vickle, G. D., Kalback, W. M., etal. (2009). Amyloid beta peptides in human plasma and tissues and their significance for Alzheimer's disease. Alzheimers Dement. 5, 18-29. doi: 10.1016/j.jalz.2008.10.004 
Rojas-Fernandez, C. H., and Cameron, J. C. (2012). Is statin-associated cognitive impairment clinically relevant? A narrative review and clinical recommendations. Ann. Pharmacother. 46, 549-557. doi: 10.1345/aph.1Q620

Rotwein, P., Burgess, S. K., Milbrandt, J. D., and Krause, J. E. (1988). Differential expression of insulin-like growth factor genes in rat central nervous system. Proc. Natl. Acad. Sci. U.S.A. 85, 265-269. doi: 10.1073/pnas.85.1.265

Sato, N., and Morishita, R. (2013). Plasma abeta: a possible missing link between Alzheimer disease and diabetes. Diabetes 62, 1005-1006. doi: $10.2337 / \mathrm{db} 12-1549$

Sato, N., Takeda, S., Uchio-Yamada, K., Ueda, H., Fujisawa, T., Rakugi, H., etal. (2011). Role of insulin signaling in the interaction between Alzheimer disease and diabetes mellitus: a missing link to therapeutic potential. Curr. Aging Sci. 4, 118-127. doi: 10.2174/1874609811104020118

Sato, N., Okochi, M., Taniyama, Y., Kurinami, H., Shimamura, M. Takeuchi, D., et al. (2006). Development of new screening system for Alzheimer disease, in vitro Abeta sink assay, to identify the dissociation of soluble Abeta from fibrils. Neurobiol. Dis. 22, 487-495. doi: 10.1016/j.nbd.2005.12.010

Sato, N., Okochi, M., Shinohara, M., Thinakaran, G., Takeda, S. Fukumori, A., et al. (2012a). Differential regulation of amyloid precursor protein/presenilin 1 interaction during $\mathrm{Ab} 40 / 42$ production detected using fusion constructs. PLoS ONE 7:e48551. doi: 10.1371/journal.pone. 0048551

Sato, N., Shinohara, M., Rakugi, H., and Morishita, R. (2012b). Dual effects of statins on Abeta metabolism: upregulation of the degradation of APP-CTF and Abeta clearance. Neurodegener. Dis. 10, 305-308. doi: 10.1159/000334534

Schechter, R., Beju, D., and Miller, K. E. (2005). The effect of insulin deficiency on tau and neurofilament in the insulin knockout mouse. Biochem. Biophys. Res. Commun. 334, 979-986. doi: 10.1016/j.bbrc.2005.07.001

Schubert, M., Brazil, D. P., Burks, D. J., Kushner, J. A., Ye, J., Flint, C. L., et al. (2003). Insulin receptor substrate2 deficiency impairs brain growth and promotes tau phosphorylation. J. Neurosci. 23, 7084-7092.

Schubert, M., Gautam, D., Surjo, D., Ueki, K., Baudler, S., Schubert, D., et al. (2004). Role for neuronal insulin resistance in neurodegenerative diseases. Proc Natl. Acad. Sci. U.S.A. 101, 31003105. doi: 10.1073/pnas.0308724101 Shemer, J., Raizada, M. K., Masters, B. A., Ota, A., and LeRoith, D. (1987). Insulin-like growth factor I receptors in neuronal and glial cells. Characterization and biological effects in primary culture. J. Biol. Chem. 262, 7693-7699.

Shepardson, N. E., Shankar, G. M., and Selkoe, D. J. (2011a). Cholesterol level and statin use in Alzheimer disease: I. Review of epidemiological and preclinical studies. Arch. Neurol. 68, 1239-1244. doi: 10.1001/archneurol.2011.203

Shepardson, N. E., Shankar, G. M., and Selkoe, D. J. (2011b). Cholesterol level and statin use in Alzheimer disease: II. Review of human trials and recommendations. Arch. Neurol. 68, 1385-1392. doi: 10.1001/archneurol.2011.242

Sherin, A., Anu, J., Peeyush, K. T., Smijin, S., Anitha, M., Roshni, B. T., et al. (2012). Cholinergic and GABAergic receptor functional deficit in the hippocampus of insulin-induced hypoglycemic and streptozotocin-induced diabetic rats. Neuroscience 202: 69-76. doi: 10.1016/j.neuroscience.2011.11.058

Sherrington, R., Rogaev, E. I., Liang, Y., Rogaeva, E. A., Levesque, G. Ikeda, M., et al. (1995). Cloning of a gene bearing missense mutations in early-onset familial Alzheimer's disease. Nature 375, 754-760. doi: 10.1038/375754a0

Shibata, M., and Yasuda, B. (1980) New experimental congenital diabetic mice (N.S.Y. mice). Tohoku J. Exp. Med. 130, 139-142. doi: 10.1620/tjem.130.139

Shimamura, M., Sato, N., Sata, M., Kurinami, H., Takeuchi, D., Wakayama, K., et al. (2007). Delayed postischemic treatment with fluvastatin improved cognitive impairment after stroke in rats. Stroke 38, 3251-3258. doi: 10.1161/STROKEAHA.107.485045

Shinohara, M., Sato, N., Kurinami, H., Takeuchi, D., Takeda, S., Shimamura, M., et al. (2010). Reduction of brain beta-amyloid (Abeta) by fluvastatin, a hydroxymethylglutaryl-CoA reductase inhibitor, through increase in degradation of amyloid precursor protein C-terminal fragments (APP-CTFs) and Abeta clearance. $J$. Biol. Chem. 285, 22091-22102. doi: 10.1074/jbc.M110.102277

Shlyakhto, E. (2007). Observational study on cognitive function and systolic blood pressure reduction (OSCAR): preliminary analysis of 6-month data from $>10,000$ patients and review of the literature. Curr. Med. Res. Opin. 23(Suppl. 5), S13-S18. doi: 10.1185/ 030079907X260719

Skoog, I., Lernfelt, B., Landahl, S. Palmertz, B., Andreasson, L. A., Nilsson, L., et al. (1996). 15-Year longitudinal study of blood pressure and dementia. Lancet 347, 11411145. doi: 10.1016/S0140-6736(96) 90608-X

Skoog, I., Lithell, H., Hansson, L. Elmfeldt, D., Hofman, A., Olofsson, B., etal. (2005). Effect of baseline cognitive function and antihypertensive treatment on cognitive and cardiovascular outcomes: study on COgnition and Prognosis in the Elderly (SCOPE). Am. J. Hypertens. 18, 1052-1059. doi: 10.1016/j.amjhyper.2005.02.013

Son, S. M., Song, H., Byun, J., Park, K. S, Jang, H. C., Park, Y. J., et al. (2012). Accumulation of autophagosomes contributes to enhanced amyloidogenic APP processing under insulinresistant conditions. Autophagy 8 1842-1844. doi: 10.4161/auto.21861

Sontag, E., Nunbhakdi-Craig, V., Lee, G., Bloom, G. S., and Mumby, M. C. (1996). Regulation of the phosphorylation state and microtubulebinding activity of Tau by protein phosphatase 2A. Neuron 17, 12011207. doi: $10.1016 / \mathrm{S} 0896-6273(00)$ 80250-0

Sparks, D. L., Scheff, S. W., Hunsaker, J. C. III, Liu, H., Landers, T., and Gross, D. R. (1994). Induction of Alzheimerlike beta-amyloid immunoreactivity in the brains of rabbits with dietary cholesterol. Exp. Neurol. 126, 88-94. doi: 10.1006/exnr.1994.1044

Sparks, D. L., Scheff, S. W., Liu, H., Landers, T. M., Coyne, C. M., and Hunsaker, J. C. III. (1995). Increased incidence of neurofibrillary tangles (NFT) in non-demented individuals with hypertension. J. Neurol. Sci. 131, 162-169. doi: 10.1016/0022510X(95)00105-B

Stewart, R., Xue, Q. L., Masaki, K. Petrovitch, H., Ross, G. W., White, L. R., et al. (2009). Change in blood pressure and incident dementia: a 32 year prospective study. Hypertension 54, 233-240. doi: 10.1161/HYPERTENSIONAHA.109.128744

Sun, X. J., Rothenberg, P., Kahn, C. R., Backer, J. M., Araki, E., Wilden, P. A., etal. (1991). Structure of the insulin receptor substrate IRS1 defines a unique signal transduction protein. Nature 352, 73-77. doi: 10.1038/352073a0

Sutherland, C., Leighton, I. A., and Cohen, P. (1993). Inactivation of glycogen synthase kinase-3 beta by phosphorylation: new kinase connections in insulin and growth-factor signalling. Biochem. J. 296(Pt 1), 15-19.

Takeda, S., Sato, N., Ogihara, T., and Morishita, R. (2008). The renin-angiotensin system, hypertension and cognitive dysfunction in Alzheimer's disease: new therapeutic potential. Front. Biosci. 13:22532265. doi: $10.2741 / 2839$

Takeda, S., Sato, N., Takeuchi, D., Kurinami, H., Shinohara, M., Niisato, K., etal. (2009a). Angiotensin receptor blocker prevented beta-amyloid-induced cognitive impairment associated with recovery of neurovascular coupling. Hypertension 54, 1345-1352. doi: 10.1161/HYPERTENSIONAHA.109. 138586

Takeda, S., Sato, N., Uchio-Yamada, K., Sawada, K., Kunieda, T., Takeuchi, D., etal. (2009b). Elevation of plasma beta-amyloid level by glucose loading in Alzheimer mouse models. Biochem. Biophys. Res. Commun. 385, 193-197. doi: 10.1016/j.bbrc.2009.05.037

Takeda, S., Sato, N., Rakugi, H., and Morishita, R. (2010a). Plasma betaamyloid as potential biomarker of Alzheimer disease: possibility of diagnostic tool for Alzheimer disease. Mol. Biosyst. 6, 1760-1766. doi: $10.1039 / \mathrm{c} 003148 \mathrm{~h}$

Takeda, S., Sato, N., Uchio-Yamada, K., Sawada, K., Kunieda, T., Takeuchi, D., et al. (2010b). Diabetes-accelerated memory dysfunction via cerebrovascular inflammation and Abeta deposition in an Alzheimer mouse model with diabetes. Proc. Natl. Acad. Sci. U.S.A. 107, 7036-7041. doi: 10.1073/pnas.1000645107

Takeda, S., Sato, N., Rakugi, H., and Morishita, R. (2011). Molecular mechanisms linking diabetes mellitus and Alzheimer disease: beta-amyloid peptide, insulin signaling, and neuronal function. Mol. Biosyst. 7, 1822 1827. doi: $10.1039 / \mathrm{c} 0 \mathrm{mb} 00302 \mathrm{f}$

Takeda, S., Sato, N., Uchio-Yamada, K., Yu, H., Moriguchi, A., Rakugi, H., et al. (2012). Oral glucose loading modulates plasma beta-amyloid level in Alzheimer's disease patients: potential diagnostic method for Alzheimer's disease. Dement. Geriatr. Cogn. Disord. 34, 25-30. doi: $10.1159 / 000338704$

Talbot, K., Wang, H. Y., Kazi, H., Han, L. Y., Bakshi, K. P., Stucky, A., et al. (2012). Demonstrated brain insulin resistance in Alzheimer's disease patients is associated with IGF-1 resistance, IRS-1 dysregulation, and 
cognitive decline. J. Clin. Invest. 122, 1316-1338. doi: 10.1172/JCI5 9903

Tokutake, T., Kasuga, K., Yajima, R., Sekine, Y., Tezuka, T., Nishizawa, M., et al. (2012). Hyperphosphorylation of tau induced by naturally secreted amyloid-beta at low nanomolar concentrations is modulated by insulin-dependent AKTGSK3beta signaling pathway. J. Biol. Chem. 287, 35222-35233. doi: 10.1074/jbc.M112.348300

Ueda, H., Ikegami, H., Kawaguchi, Y., Fujisawa, T., Nojima, K., Babaya, N., et al. (2000). Age-dependent changes in phenotypes and candidate gene analysis in a polygenic animal model of Type II diabetes mellitus; NSY mouse. Diabetologia 43, 932-938. doi: 10.1007/s001250051472

van de Nes, J. A., Kamphorst, W., Ravid, R., and Swaab, D. F. (1998). Comparison of beta-protein/A4 deposits and Alz-50-stained cytoskeletal changes in the hypothalamus and adjoining areas of Alzheimer's disease patients: amorphic plaques and cytoskeletal changes occur independently. Acta
Neuropathol. 96, 129-138. doi: $10.1007 / \mathrm{s} 004010050872$

van Elderen, S. G., de Roos, A., de Craen, A. J., Westendorp, R. G., Blauw, G. J., Jukema, J. W., et al. (2010). Progression of brain atrophy and cognitive decline in diabetes mellitus: a 3-year followup. Neurology 75, 997-1002. doi: 10.1212/WNL.0b013e3181f25f06

Wagstaff, L. R., Mitton, M. W., Arvik, B. M., and Doraiswamy, P. M. (2003). Statin-associated memory loss: analysis of 60 case reports and review of the literature. Pharmacotherapy 23, 871-880. doi: 10.1592/phco.23.7.871.32720

Wang, J., Ho, L., Chen, L., Zhao, Z., Zhao, W., Qian, X., et al. (2007). Valsartan lowers brain beta-amyloid protein levels and improves spatial learning in a mouse model of Alzheimer disease. J. Clin. Invest. 117, 3393-3402. doi: 10.1172/JCI 31547

Whitmer, R. A., Karter, A. J., Yaffe, K., Quesenberry, C. P. Jr., and Selby, J. V. (2009). Hypoglycemic episodes and risk of dementia in older patients with type 2 diabetes mellitus. JAMA 301, 1565-1572. doi: 10.1001/jama.2009.460

Wickelgren, I. (1998). Tracking insulin to the mind. Science 280, 517-519. doi: 10.1126/science.280.5363.517

Wolozin, B., Kellman, W., Ruosseau, P., Celesia, G. G., and Siegel, G. (2000). Decreased prevalence of Alzheimer disease associated with 3hydroxy-3-methyglutaryl coenzyme A reductase inhibitors. Arch. Neurol. 57, 1439-1443. doi: 10.1001/archneur.57.10.1439

Wyss, M. T., Jolivet, R., Buck, A., Magistretti, P. J., and Weber, B. (2011). In vivo evidence for lactate as a neuronal energy source. J. Neurosci. 31, 7477-7485. doi 10.1523/JNEUROSCI.0415-11.2011

Zhang, Y., Zhou, B., Deng, B., Zhang, F., Wu, J., Wang, Y., et al. (2013). Amyloid-beta induces hepatic insulin resistance in vivo via JAK2. Diabetes 62, 1159-1166. doi: $10.2337 / \mathrm{db} 12$ 0670

Conflict of Interest Statement: The authors declare that the research was conducted in the absence of any commercial or financial relationships that could be construed as a potential conflict of interest.

Received: 09 April 2013; accepted: 08 October 2013; published online: 05 November 2013.

Citation: Sato $N$ and Morishita $R$ (2013) Roles of vascular and metabolic components in cognitive dysfunction of Alzheimer disease: short- and long-term modification by non-genetic risk factors. Front. Aging Neurosci. 5:64. doi: 10.3389/fnagi.2013.00064

This article was submitted to the journal Frontiers in Aging Neuroscience. Copyright (c) 2013 Sato and Morishita. This is an open-access article distributed under the terms of the Creative Commons Attribution License (CC BY). The use, distribution or reproduction in other forums is permitted, provided the original author(s) or licensor are credited and that the original publication in this journal is cited, in accordance with accepted academic practice. No use, distribution or reproduction is permitted which does not comply with these terms. 